\title{
Involvement of the AMPA Receptor GluR-C Subunit in Alcohol-Seeking Behavior and Relapse
}

\author{
Carles Sanchis-Segura, ${ }^{1}$ Thilo Borchardt, ${ }^{2}$ Valentina Vengeliene, ${ }^{1}$ Tarek Zghoul, ${ }^{1}$ Daniel Bachteler, ${ }^{1}$ Peter Gass, ${ }^{1}$ \\ Rolf Sprengel, ${ }^{2}$ and Rainer Spanage ${ }^{1}$ \\ ${ }^{1}$ Department of Psychopharmacology, Central Institute of Mental Health, University of Heidelberg, 68072 Mannheim, Germany, and ${ }^{2}$ Department of \\ Molecular Neuroscience, Max Planck Institute for Medical Research, D-69120 Heidelberg, Germany
}

Craving and relapse are core symptoms of drug addiction and alcoholism. It is suggested that, after chronic drug consumption, longlasting neuroplastic changes within the glutamatergic system are important determinants of addictive behavior. Here, we show that the AMPA type glutamate receptor plays a crucial role in alcohol craving and relapse. We observed, in two animal models of alcohol craving and relapse, that the AMPA antagonist GYKI 52466 [1-(4-aminophenyl)-4-methyl-7,8-methylenedioxy-5H-2,3-benzodiazepine] dosedependently reduced cue-induced reinstatement of alcohol-seeking behavior and the alcohol deprivation effect. The involvement of the AMPA receptor in these phenomena was further studied using mice deficient for the GluR-C AMPA subunit [GluR-C knock-out (KO)]. GluR-C KOs displayed a blunted, cue-induced reinstatement response and alcohol deprivation effect, when compared with wild-type controls; however, no differences between genotypes could be observed regarding ethanol self-administration under operant or home cage drinking conditions. These results imply a role for GluR-C in alcohol relapse, although this phenotype could also be attributable to a reduction in the total number of AMPA receptors in specific brain areas. In conclusion, AMPA receptors seem to be involved in the neuroplastic changes underlying alcohol seeking behavior and relapse. Thus, AMPA receptors represent a novel therapeutic target in preventing relapse.

Key words: AMPA; ethanol relapse; alcohol deprivation effect (ADE); reinstatement; GluR-C; addiction

\section{Introduction}

Glutamatergic neurotransmission and its neuroadaptive changes have been proposed as important molecular determinants of craving and relapse (Cornish and Kalivas, 2000; Tzschentke and Schmidt, 2003). In particular, it is suggested that a hyperglutamatergic state mediates, at least in part, alcohol relapse behavior (Tsai and Coyle, 1998). Thus, acamprosate, a drug used to prevent relapse in alcoholic patients (Mann, 2004), is thought to act via dampening a hyperglutamatergic state in the alcoholaddicted brain (Littleton, 1995; Dahchour and De Witte, 2000, 2003; Spanagel et al., 2005). In alcohol relapse, the possible involvement of the NMDA (Hölter et al., 2000; Krystal et al., 2003; Bachteler and Spanagel, 2005) and metabotropic glutamate receptors has previously been assessed (Bäckstrom et al., 2004; Olive et al., 2005; Schroeder et al., 2005), but little is known about

Received July 4, 2005; revised Nov. 22, 2005; accepted Nov. 22, 2005.

This work was supported by Bundesministerium für Bildung und Forschung Grants FKZ01GS0475 and 01 EB 0410 (to R.S.), European Community Grant TARGALC QLG3-CT-2002-01048 (to R.S.), Sonderforschungsbereich (SFB) Grants 636/B1 and 636/A4 (to R.S.), and SFB Grant 636/B3 (to P.G.). We thank Sabrina Koch for her excellent technical assistance.

${ }^{*}$ C.S.-S. and T.B. contributed equally to this work.

Correspondence should be addressed to Dr. Carles Sanchis-Segura, Department of Psychopharmacology, Central Institute for Mental Health, University of Heidelberg, J5, D-68159 Mannheim, Germany. E-mail: segura@zi-mannheim.de.

T. Borchardt's present address: Max-Planck-Institut für Herz- und Lungenforschung, 61231 Bad Nauheim, Germany.

DOI:10.1523/JNEUROSCI.4237-05.2006

Copyright $\odot 2006$ Society for Neuroscience $\quad$ 0270-6474/06/261231-08\$15.00/0 the involvement of AMPA receptors (Cowen et al., 2003). However, reinstatement of cocaine-seeking behavior is attenuated by the administration of an AMPA receptor antagonist (Cornish and Kalivas, 2000), and responding to cocaine-associated cues under a second-order schedule decreased after a pharmacological blockade of AMPA receptors (Di Ciano and Everitt, 2001).

Here, we studied alcohol seeking and relapse behavior in two behavioral models: the "cue-induced reinstatement model" and the "alcohol deprivation effect" (ADE) (Spanagel and Hölter, 1999; Le and Shaham, 2002). Previous studies using these models suggested the involvement of glutamate in relapse behavior (for review, see Bachteler and Spanagel, 2005). In the present study, we show that the AMPA receptor is critically involved in alcohol seeking and relapse, because the AMPA receptor antagonist 1(4-aminophenyl)-4-methyl-7,8-methylenedioxy-5 H-2,3-benzodiazepine (GYKI 52466) blunted reinstatement behavior and ADE. The involvement of AMPA receptors in this behavior was further characterized by a second set of independent experiments using mice deficient in the AMPA receptor subunit GluR-C. We focused our interest on this AMPA receptor subunit, because it was shown recently that, in rats, the GluR-C subunit is upregulated during alcohol abstinence (Brückner et al., 1997). This is also observed in the cerebral cortex of adult guinea pigs after prenatal ethanol exposure (Dettmer et al., 2003). In these studies, the expression of other AMPA receptor subunits (GluR-A and GluR-B) was not consistently affected by alcohol exposure, whereas the GluR-D subunit was not analyzed. The results of this 
second set of experiments confirmed the involvement of AMPA receptors and particularly those containing the GluR-C subunit.

\section{Materials and Methods}

Animals. For the pharmacological studies, two-month-old male Wistar rats from our own breeding colony at the Central Institute for Mental Health (Mannheim, Germany) were used. Homozygous GluR-C knockout (GluR-C KO) and wild-type (WT) male mice were generated as described below and bred at the Max Planck Institute of Medical Research in Heidelberg. For the behavioral experiments, male GluR-C knock-outs and their wild-type littermates from at least six consecutive backcrosses with $\mathrm{C} 57 \mathrm{BL} / 6 \mathrm{~N}$ were used.

All animals were singly housed in standard hanging cages at $21 \pm 1^{\circ} \mathrm{C}$ and $50 \pm 5 \%$ relative humidity on a $12 \mathrm{~h}$ light/dark cycle, with lights on at 7:00 A.M. Animals were provided with standard rodent food and tap water ad libitum. Animals were handled on a daily basis before starting the experiments. All experimental procedures were approved by the Committee on Animal Care and Use and performed in accordance with the local Animal Welfare Act and the European Communities Council Directive 86/609/EEC of November 24, 1986.

Generation of GluR-C knock-out mice. A rat cDNA probe with exons 11-13 was used to screen a 129/SV mouse-phage genomic library $(\lambda$ FixII; Stratagene, Heidelberg, Germany). For the targeting vector, an 11.7 $\mathrm{kb}$ fragment of the X-chromosomally encoded murine GluR-C gene (Gria3) harboring parts of intron 10 and 11 and exon 11 into pBluescriptII. Exon 11 includes the coding information for the essential channel pore regions M1 and M2. Next, in intron 11, a short 64 bp BsrGI-PshAI fragment was replaced by a $1.7 \mathrm{~kb}$ DNA fragment, which encoded the phosphoglycerate kinase-neomycin (pgk-neo) selection marker (from plasmid pNeolox-5171) flanked by loxP5171 sites (Lee and Saito, 1998). In addition, 900 bp upstream of exon 11 a 24 bp BglII-AvrII fragment was replaced by a $46 \mathrm{bp}$ fragment encoding an $\mathrm{Nco}$ I restriction site and one loxP5171 element. Four silent mutations were introduced into exon 11. For electroporation of R1-embryonic stem (ES) cells, the targeting vector was linearized at a unique $\mathrm{PacI}$ restriction enzyme recognition site at the $3^{\prime}$ end of the long arm. Neomycin-resistant ES clones were screened for homologous recombination events by nested PCR with outside-inside primer pairs. Positive clones were confirmed by Southern blotting with a 450 bp PacI-SacI 3' outside probe after digestion with BglII and a 480 bp AvrIIBstZ17 fragment as an inside probe after $\mathrm{NcoI}$ digestion (data not shown).

GluR-C ${ }^{310 x}$ ES cell clone P59K1 was injected into C57BL/6N blastocysts, and chimeric males were backcrossed with $\mathrm{C} 57 \mathrm{BL} / 6 \mathrm{~N}$ females. Heterozygous GluR-C $\mathrm{C}^{3 l o x /+}$ female offspring were then crossed with Cre-deleter (Schwenk et al., 1995) mice to generate heterozygous GluR$\mathrm{C}^{1 \text { lox/+ }}$ female mice, which were backcrossed to C57BL/6N to generate female GluR-C $\mathrm{C}^{1 \text { lox/+ }}$ and hemizygous GluR-C ${ }^{\text {llox }}$ genotypes. After intercrosses of homozygous (GluR-C $\left.{ }^{1 \text { lox/1lox }}\right)(G l u R-C \mathrm{KO})$ mice were obtained with the expected Mendelian ratio. Genotyping of GluR-C KO mice were performed by PCR with primers P1 (GGT AGA TAC TGA AGC ATA GCT ATG C) and P4 (GGT ATA TCT TCC CAG CCC CAA G) to amplify a 260 bp GluR-C ${ }^{1 \text { lox }}$ fragment, primers P2 (CCA ATG TTG TGC TTT AGC CTT TGC) and P4 to amplify a $240 \mathrm{bp} \mathrm{WT} \mathrm{fragment,} \mathrm{and}$ P3 (CAC TTT GTG GTT CTA AGT ACT GTG G) and P4 to amplify a 270 bp GluR-C ${ }^{3 l o x}$ fragment.

Verification of the deletion. The absence of GluR-C was confirmed by Western blot of brain extracts using a monoclonal antibody directed against the N-terminal portion of GluR-C. Total brains of mice [postnatal day 15 (P15)] were homogenized in 25 mM HEPES, pH 7.4, containing protease inhibitor cocktail (Roche Diagnostics, Mannheim, Germany). After determination of protein amount by BCA-assay (Pierce, Rockford, IL), $10 \mu \mathrm{g}$ of total protein was separated on 7.5\% SDS-PAGE and blotted onto nitrocellulose membranes (PA 85; Schleicher \& Schuell BioScience, Dassel, Germany). Blots were incubated with monoclonal anti-glutamate receptor 3 antibody (1:600; 32-0400; Zymed Laboratories, South San Francisco, CA) in PBS-T (PBS, $0.5 \%$ Tween 20 )/8\% dry milk for $2 \mathrm{~h}$ at room temperature (RT), detected with peroxidase-coupled goat antimouse antibody (1:15,000; Dianova, Hamburg, Germany) for $45 \mathrm{~min}$ at RT and developed by ECL-Plus (Amersham Biosciences, Freiburg, Germany).
Expression of AMPA receptor subunits in WT and GluR-C KO mice. Expression of the AMPA receptor subunits GluR-A, GluR-B, GluR-C, and GluR-D in hippocampi and cerebelli of WT and GluR-C KO was assessed by Western blot. These brain areas were selected because they express differential (low vs high levels) proportions of GluR-C -subunitcontaining AMPA receptors (Tsuzuki et al., 2001; Sans et al., 2003), a factor that could determine the presence or absence of adaptive changes after the genetic deletion of this subunit. For similar reasons, this assessment was performed at different development times from P2 to P90. Total protein of the hippocampi and the cerebelli was isolated, and for each sample, $10 \mu \mathrm{g}$ of protein was separated in a $7.5 \%$ SDS-PAGE and transferred on nitrocellulose. The glutamate receptor subunits were recognized by selective antibodies and monitored by autoradiography. The $\alpha$-subunit of the $\alpha$-CaMKII $\left(\mathrm{Ca}^{2+} /\right.$ calmodulin-dependent protein kinase II) and $\beta$ III-tubulin was used as a positive control for developmental controlled gene expression in the hippocampus and cerebellum, respectively. Loading was controlled by $\beta$-actin. The experiment was repeated with at least three sets of mice.

Drugs. Alcohol drinking solutions were prepared from $96 \%$ ethanol [Merck (Darmstadt, Germany) KgaA] and then diluted with tap water. 4-(8-Methyl-9H-1,3-dioxolo[4,5-h][2,3] benzodiazepin-5-yl)benzenamine hydrochloride (GYKI 52466 hydrochloride; Tocris, Ellisville, MO) was dissolved in aqua ad iniectabilia (B Braun Melsungen, Melsungen, Germany), slightly acidified with $\mathrm{HCl}$. The solutions were freshly prepared before each treatment and injected in a volume of $3 \mathrm{ml} / \mathrm{kg}$ intraperitoneally. Control groups were injected with an equivalent volume of this vehicle.

Cue-induced reinstatement in rats. Rat training and testing procedures took place in eight operant chambers (MED Associates, St. Albans, VT), enclosed in ventilated sound-attenuating cubicles. The chambers were equipped with a response lever on each side panel of the chamber. Responses at the lever activated a syringe pump that delivered a $30 \mu \mathrm{ldrop}$ of fluid into a liquid receptacle, situated next to the levers (delivery time, $1 \mathrm{~s})$. A stimulus light was available above the right response lever, with a loudspeaker at the top left-hand side of the self-administration chamber to provide the contingent presentation of conditioned stimuli accompanying each reinforcer delivery (water or ethanol, respectively; see below).

Twenty-four Wistar rats were trained in a fixed-ratio [fixed ratio 1 (FR1)] oral ethanol (10\% v/v) self-administration protocol using a saccharin fading procedure, as described by Bachteler et al. (2005). Each session lasted $30 \mathrm{~min}$, with five daily sessions per week. Once the selfadministration behavior became stable, the conditioning phase was commenced. This phase involved a total of 20 sessions. In 10 of these sessions (signaled by an orange odor, $\mathrm{S}^{+}$), ethanol was available, and each press of the appropriate lever triggered an ethanol delivery accompanied by a $5 \mathrm{~s}$ light stimulus $\left(\mathrm{CS}^{+}\right)$. The alternate nonreward sessions were signaled by anise odor $\left(\mathrm{S}^{-}\right)$and pressing the corresponding lever resulted in water delivery accompanied by a $5 \mathrm{~s}$ auditory stimulus ("beep," $\mathrm{CS}^{-}$). During the first $3 \mathrm{~d}$ of this conditioning phase, the rats experienced ethanol sessions only. Subsequently, ethanol and water sessions were randomly conducted for a total of 20 sessions. After completion of this conditioning phase, rats were subjected to 12 consecutive extinction sessions (no odors were presented, and levers were available, but no consequences were programmed), which were sufficient to attain our a priori extinction criterion $(<10$ lever responses per session). According to values observed at the 12th extinction session, the rats were assigned to three different matched groups. In the next $2 \mathrm{~d}$, reinstatement of the operant response was assessed.

For the reinstatement tests, rats were injected with vehicle or GYKI 52466 ( $4 \mathrm{or} 10 \mathrm{mg} / \mathrm{kg}$ ) $30 \mathrm{~min}$ before they were placed into the operant chambers. The sessions were initiated by extension of both levers and presentation of either the ethanol- or water-associated smells. Responses at the corresponding lever were followed by activation of the syringe pump and presentation of the $\mathrm{CS}^{+}$(stimulus light) in the $\mathrm{S}^{+}$condition or the $\mathrm{CS}^{-}$(beep) in the $\mathrm{S}^{-}$condition, but liquids (alcohol or water) were not made available. One-half of the animals in each group were tested under the $\mathrm{S}^{+} / \mathrm{CS}^{+}$condition on day 1 and under the $\mathrm{S}^{-} / \mathrm{CS}^{-}$ condition on day 2. For the second half of each group, conditions were reversed. 
$A D E$ in rats. Ethanol consumption in a nonoperant free-choice paradigm was evaluated in accordance with the procedure described by Vengeliene et al. (2005). After $>40$ weeks of access to alcohol, a 3 d stable baseline was established. Then, the alcohol bottles were removed from the cages, leaving the animals with ad libitum access to food and water. Twenty days after ethanol removal, rats were assigned to three matched groups according to their baseline (before deprivation) ethanol consumption, with every rat receiving the first injection of vehicle or GYKI 52466 ( 4 or $10 \mathrm{mg} / \mathrm{kg}$ ) at 7:00 P.M. At day 21, the alcohol bottles were reintroduced, and ethanol and water consumption was measured for 3 additional days, during which all animals received two daily injections (at 7:00 A.M. and at 7:00 P.M.). To assess any possible toxic effect of this treatment, each rat's body weight was recorded $24 \mathrm{~h}$ before the first injection and $12 \mathrm{~h}$ after the last injection.

Behavioral characterization of GluR-C knock-out mice. Because this is the first study involving these knock-out mice, locomotion and motor performance, exploration, novelty reactivity, anxiety, and learning/ memory abilities were assessed in $30 \mathrm{WT}$ and $34 \mathrm{GluR}-\mathrm{C} \mathrm{KO}$ mice. More specifically, locomotion was assessed in a square-shaped, white open field $(50 \times 50 \mathrm{~cm}$ and illuminated from above by $25 \mathrm{lux})$. Mice were placed individually into the arena and monitored for $15 \mathrm{~min}$ by a video camera. The resulting data were analyzed using the image-processing system EthoVision 1.96 (Noldus Information Technology, Wageningen, The Netherlands). Additional information about motor abilities was obtained by evaluating mice in the rotarod and the beam balance tests [for details of the protocol used, see Scherbel et al. (1999)] using, in both evaluations, the latency to fall as index of performance. Exploration/ novelty reaction was assessed in the novel cage test (counting the number of rearings within the first $5 \mathrm{~min}$ after placing the animal into a new standard type II macrolon cage with a thin layer of bedding material). Anxiety-related behaviors were assessed in the zero maze and the light/ dark box test. The zero maze consisted of a gray plastic annular runway (width, $6 \mathrm{~cm}$; outer diameter, $46 \mathrm{~cm} ; 50 \mathrm{~cm}$ above ground level). Two opposing $90^{\circ}$ sectors were protected by inner and outer walls of gray polyvinyl chloride (height, $10 \mathrm{~cm}$ ). Animals were placed in one of the protected sectors and observed for $5 \mathrm{~min}$. The maze was illuminated by an intensity of 25 lux. The light/dark box consisted of two plastic chambers, connected by a small tunnel. One of the chambers, measuring $20 \times$ $15 \mathrm{~cm}$, was dark because it was covered by a lid. The other chamber, measuring $30 \times 15 \mathrm{~cm}$, was white and illuminated from the top with an intensity of 600 lux. Mice were placed into the dark compartment, and latency to first exit, total number of exits, and time in the light compartment were recorded for $5 \mathrm{~min}$. Finally, memory/learning abilities were evaluated by means of the Morris water maze test. For additional details of the protocols used in this behavioral test battery, see Chourbaji et al. (2004).

Cue-induced reinstatement in GluR-C knock-out mice. Mice were trained and tested in eight operant chambers (TSE Systems, Bad Homburg, Germany), operated with operant behavior system (TSE Systems). Each chamber had two ultrasensitive levers (required force, $\leq 1 \mathrm{~g}$ ). When the programmed ratio requirements were met on the active lever, $20 \mu \mathrm{l}$ of the ethanol solution were delivered into a microreservoir. The delivery was accomplished within a second, and a yellow light located above the microreservoir was turned on during the delivery time.

One week after arrival at the colony room, $13 \mathrm{WT}$ and 13 GluR-C KO mice were trained to self-administer ethanol by using a standard sucrose fading procedure with a schedule of continuous (FR1) reinforcement. In the subsequent 3 weeks, animals were exposed to five weekly selfadministration sessions, in which pressing the lever (FR1) resulted in the delivery of $20 \mu \mathrm{l}$ of a $10 \%(\mathrm{v} / \mathrm{v})$ ethanol solution and the presentation of a discriminative stimulus (light) during the delivery time ( $1 \mathrm{~s}$ ), with every session lasting $30 \mathrm{~min}$, as did all sessions throughout the study. Fifteen extinction sessions were conducted over 3 weeks, which were sufficient in reaching our a priori extinction criterion $(<30 \%$ responding of previous baseline responding). Extinction sessions were identical to those of the self-administration phase, except that both levers had no programmed consequences. Two days after the last extinction session, reinstatement was assessed in a single session, initiated by a noncontingent presentation of the conditioned stimulus (light), in which lever presses were not fol-
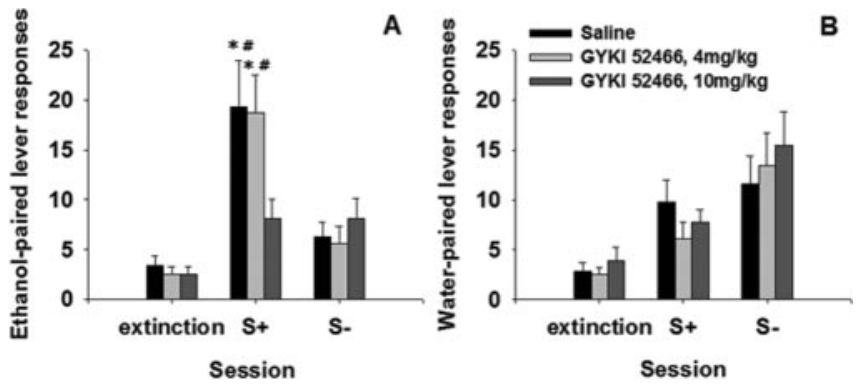

Figure 1. Effects of the AMPA receptor antagonist GYKI 54266 on cue-induced reinstatement of ethanol-seeking behavior in Wistar rats ( $n=8$ per group). Data are shown as mean \pm SEM of the reinforced lever presses after the presentation of a composed stimulus, paired previously with ethanol $\left(\boldsymbol{S}^{+} / \mathrm{CS}^{+} ; \boldsymbol{A}\right)$ or water $\left(\boldsymbol{S}^{-} / \mathrm{CS}^{-} ; \boldsymbol{B}\right)$ availability (for details, see Materials and Methods). ( ${ }^{*} p<0.01$ compared with the last extinction session; ${ }^{*} p<0.01$ compared with GYKI $546610 \mathrm{mg} / \mathrm{kg})$.

lowed by ethanol delivery or by light presentation. In the absence of previous studies assessing cue-induced reinstatement for ethanol in mice (Spanagel and Sanchis-Segura, 2003), the details of this protocol were chosen based on our own pilot studies.

ADE in GluR-C knock-out mice. An additional cohort of $26 \mathrm{WT}$ and 32 GluR-C KO mice were trained to drink ethanol in a nonrestricted twobottle free choice paradigm in which animals could choose between water and increasing concentrations of ethanol $(2,4,8,12$, and $16 \% \mathrm{v} / \mathrm{v})$ (Spanagel et al., 2005). Water (in milliliters per day) and ethanol intake (in grams per kilograms per day) as well as ethanol preference (ethanol consumption/total fluid intake) were calculated. Before assessing ADE, ethanol (16\%) consumption was allowed to continue for 14 weeks. After acquiring a stable $3 \mathrm{~d}$ baseline, access to ethanol was withdrawn for 3 weeks. At the end of the 3 week period, access to a $16 \%$ ethanol solution was reintroduced, and ethanol intake was measured daily for another $3 \mathrm{~d}$.

Statistics. All data are presented as means \pm SEM, and a significance level of $p \leq 0.05$ was used throughout this study. Mean comparisons were performed using a Student's $t$ test for independent samples, one- or two-way ANOVA with a repeated-measures factor, when necessary. Post hoc comparisons were performed using Newman-Keuls test. To prevent a possible effect of baseline differences between group reinstatement, data were transformed to percentages over these baseline values, when necessary.

\section{Results \\ Cue-induced reinstatement and ADE in rats are reduced by GYKI 52466}

After the training procedure, rats exhibited $193.2 \pm 15.0$ and $38.8 \pm 1.9$ reinforced and nonreinforced lever presses, respectively, during the last 10 operant ethanol self-administration sessions. The number of operant responses progressively faded across 12 extinction sessions. Thus, lever presses dropped in the 12 th extinction session to $3.5 \pm 0.6$ and $2.7 \pm 0.5$ for the previously reinforced and nonreinforced lever, respectively. From these data, three comparable groups corresponding to vehicle or two GYKI 52466 doses were formed and, for the subsequent $2 \mathrm{~d}$, the differential ability of the $\mathrm{S}^{+} / \mathrm{CS}^{+}$and $\mathrm{S}^{-} / \mathrm{CS}^{-}$to reinstate operant responding in the previously ethanol- and waterreinforced lever was assessed (Fig. $1 A, B$, respectively). Thus, the effects of a two-way ANOVA comparing the number of responses of these three groups on the previously ethanol-reinforced lever in each experimental condition (extinction, $\mathrm{S}^{+} / \mathrm{CS}^{+}$, and $\mathrm{S}^{-}$/ $\mathrm{CS}^{-}$) yielded a main effect of the experimental condition factor $\left(F_{(2,42)}=20.00 ; p<0.001\right)$ as well as of its interaction with the GYKI 52466 dose $\left(F_{(4,42)}=2.37 ; p<0.05\right)$. Post hoc comparisons revealed that during the $\mathrm{S}^{+} / \mathrm{CS}^{+}$session, rats treated with both vehicle and the low GYKI 52466 dose exhibited a significantly 


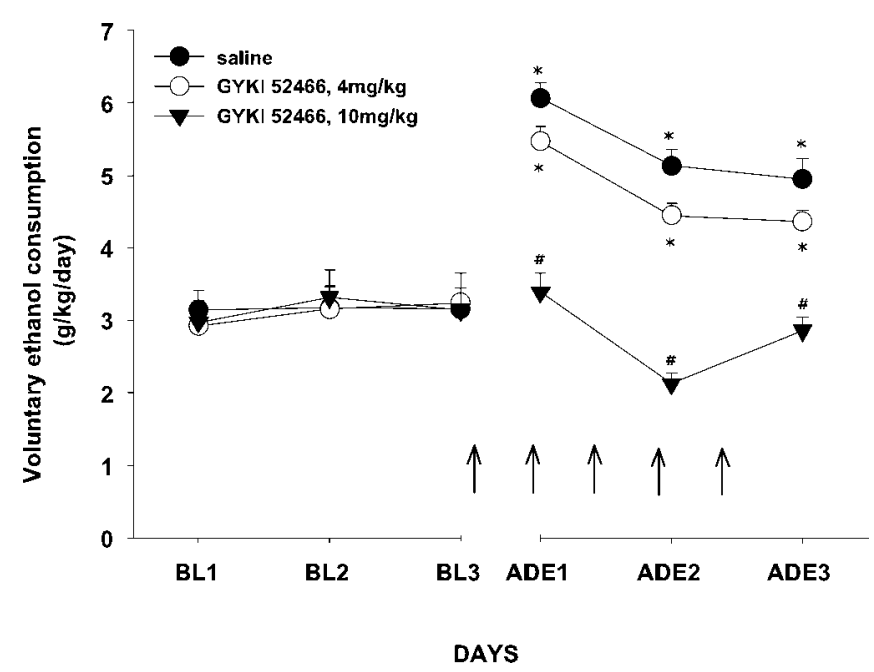

Figure 2. Effects of the AMPA antagonist GYKI 54266 on ADE in Wistar rats ( $n=8$ per group). Data are shown as mean \pm SEM ethanol consumption (grams per kilogram per day). Vehicle or GYKI 54266 injections are indicated by arrows (for details, see Materials and Methods) $\left({ }^{*} p<0.01\right.$ compared with corresponding baseline values; ${ }^{\sharp} p<0.01$ compared with saline control group). BL1, Baseline 1; BL2, baseline 2; BL3, baseline 3 .

higher number of lever presses on the previously ethanol-paired lever than that observed during both the extinction and $\mathrm{S}^{-} / \mathrm{CS}^{-}$ sessions. The number of lever presses during the $\mathrm{S}^{-} / \mathrm{CS}^{-}$reinstatement test was not different from that observed during the last extinction session, and there were not significant differences among groups. However, when data of the previously waterreinforced lever were analyzed, a two-way ANOVA (GYKI 52466 dose $X$ experimental condition) only showed a significant effect for the experimental condition factor $\left(F_{(2,42)}=20.27 ; p>0.001\right)$. Mean comparisons based on this effect revealed that, in all groups and during both reinstatement tests $\left(\mathrm{S}^{+} / \mathrm{CS}^{+}\right.$and $\left.\mathrm{S}^{-} / \mathrm{CS}^{-}\right)$, the number of lever presses on the previously water-reinforced lever was significantly higher than that observed during the last extinction session $(p<0.01)$.

Figure 2 depicts the effect of different doses of GYKI 52466 on ethanol consumption after a deprivation period (ADE) in separate groups of rats. A two-way ANOVA (group $\times$ day) yielded a significant effect of the group $\left(F_{(2,21)}=18.11 ; p<0.001\right)$ and the day $\left(F_{(5,105)}=32.83 ; p<0.001\right)$ factors as well as a significant interaction between them $\left(F_{(10,105)}=11.50 ; p<0.001\right)$. Newman-Keuls post hoc comparisons revealed that rats treated with the highest dose of GYKI 52466 did not show an increase in ethanol consumption after a deprivation period. Moreover, during the first $2 \mathrm{~d}$ after the reintroduction of alcohol, a lower dose of this compound produced a decrease in ethanol drinking that, compared with the effects of a saline injection, reached marginal statistical significance ( $p=0.06$ and $p=0.08$, respectively). These effects were observed in the absence of any variation in body weight or total fluid consumption.

\section{General behavioral characterization of GluR-C KO mice}

Figure 3 represents the constructs used in the generation of GluR-C knock-outs and the proof of GluR-C protein absence in the brains of GluR-C knock-out mice by Western blot analysis.

GluR-C KO mice did not display any major behavioral abnormalities and they were almost indistinguishable from their corresponding WT controls over a wide range of behavioral indexes assessing exploration, novelty reactivity, anxiety, and learning/ memory abilities. However, GluR-C KOs showed a slight reduc-

CAlox
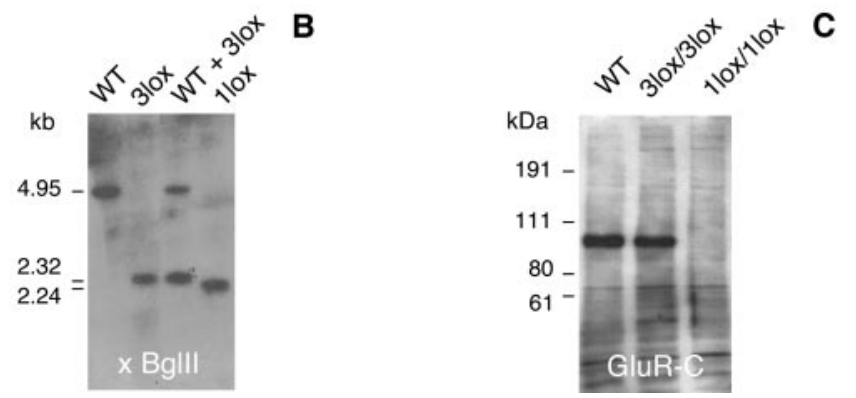

Figure 3. Generation of GluR-C knock-out mice. $A$, Schematic representation of the X-chromosomally localized WT GluR-C (WT), the targeted GluR-C ${ }^{3 l o x}$ (3lox), and the GluR-C ${ }^{\text {1lox }}$ (1lox) allele after Cre-mediated recombination. Boxes represent exon 11 and the pgk-neo selection cassette. LoxP elements are indicated by black triangles. Filled circles mark the $5^{\prime}$ and $3^{\prime}$ borders of the targeting construct. $\boldsymbol{B}$, Diagnostic $B g$ /ll restriction sites are indicated. The position of the $3^{\prime}$ outside probe for genomic Southern blot is indicated by a black bar. Primers routinely used for mouse PCR genotyping are given as P1-P4. B, Southern blot analysis of Bg/ll-digested ES cell DNA. Lanes represent, from left to right, WT ES cell DNA, positive GluR-C ${ }^{310 x}$ clone P59K1, a 1:1 mixture of WT and P59K1 DNA, and GluR-C ${ }^{10 x}$ ES cell clone \#284, obtained after transient transfection of clone P59K1 with Cre recombinase. The probe detected fragments with the expected sizes of $4.95 \mathrm{~kb}(\mathrm{WT}), 2.32 \mathrm{~kb}$ (3lox), and $2.24 \mathrm{~kb}$ (1lox), as indicated on the left. Note: R1 ES cells are of male origin. Because Gria 3 is located on the X-chromosome, there is only one copy of the GluR-C gene present. C, Western blot analysis of WT, GluR-C ${ }^{310 x}$, and GluR-C ${ }^{110 x}$ mice. Total brain lysates of 15-d-old male mice were checked for protein expression by a monoclonal antibody directed against the N-terminal portion of GluR-C. The antibody detected a prominent protein band at the expected size of $\sim 105 \mathrm{kDa}$. In GluR- $\mathrm{C}^{110 x}$ animals, no full-length or truncated forms of GluR-C could be detected. Size markers are indicated on the left in kilodaltons.

tion in locomotor activity $\left(t_{(62)}=8.03 ; p<0.01\right)$ and a poorer motor coordination $\left(t_{(62)}=2.98, p<0.05\right.$ and $t_{(62)}=4.32, p<$ 0.01 ), for rotarod and beam balance test, respectively. A summary of these findings can be found in table 1 .

\section{Possible neuroadaptive changes in GluR-C KO mice}

Hippocampal expression (Fig. 4A) of GluR-A, GluR-B, and GluR-D subunits was similar in GluR-C KO and their respective littermate control WT mice at all developmental stages tested. However, in cerebellum, genetic deletion of GluR-C was accompanied with a reduced expression of all other AMPA receptor subunits, especially in adult animals (Fig. 4B). Immunohistochemical studies revealed no appreciable alterations in the distribution of any AMPA receptor subunit in the hippocampus (supplemental Fig. 1, available at www.jneurosci.org as supplemental material) or in the cerebellum (supplemental Fig. 2, available at www.jneurosci.org as supplemental material).

\section{GluR-C KO mice exhibit reduced cue-induced reinstatement and ADE}

A two-way ANOVA (genotype $\times$ day) revealed that, across the last 10 sessions of operant ethanol self-administration, WT and GluR-C knock-out mice displayed a similar number of reinforced lever presses. Thus, a significant effect of the day factor was observed $\left(F_{(9,234)}=2.78 ; p<0.01\right)$, whereas the group factor or its interaction with the days did not reach statistical significance 
Table 1. Behavioral characterization of GluR-C KO and their respective littermate control mice

\begin{tabular}{|c|c|c|}
\hline & Wild type & GluR-C KO \\
\hline \multicolumn{3}{|l|}{ Novel cage } \\
\hline Rears/5 min & $48.08 \pm 2.17$ & $46.76 \pm 1.22$ \\
\hline \multicolumn{3}{|l|}{ Open field behavior } \\
\hline Locomotion (cm/15 min) & $7013.32 \pm 311.73$ & $5198.30 \pm 266.15^{*}$ \\
\hline Time in center (\%) & $8.10 \pm 1.11$ & $6.83 \pm 1.22$ \\
\hline Distance to wall (cm) & $4.60 \pm 0.17$ & $4.50 \pm 0.26$ \\
\hline \multicolumn{3}{|l|}{ Rotarod performance } \\
\hline Latency-to-fall first trial block (s) & $126.72 \pm 18.22$ & $72.51 \pm 12.55^{* *}$ \\
\hline Latency-to-fall 10th trial block (s) & $255.30 \pm 21.68$ & $234.50 \pm 32.27$ \\
\hline \multicolumn{3}{|l|}{ Balance beam test } \\
\hline Latency-to-fall (s) & $25.87 \pm 3.29$ & $16.01 \pm 3.52^{*}$ \\
\hline \multicolumn{3}{|l|}{ Light/dark box } \\
\hline Latency first exit (s) & $181.50 \pm 35.44$ & $150.58 \pm 35.82$ \\
\hline Total exits & $3.50 \pm 0.91$ & $3.82 \pm 1.01$ \\
\hline Time light compartment (s) & $191.00 \pm 35.94$ & $187.41 \pm 35.50$ \\
\hline \multicolumn{3}{|l|}{ 0-maze } \\
\hline Latency first exit (s) & $119.67 \pm 29.41$ & $151.93 \pm 22.45$ \\
\hline Total exits & $5.16 \pm 1.04$ & $3.75 \pm 0.68$ \\
\hline Time in open arms (s) & $29.41 \pm 3.74$ & $21.56 \pm 4.04$ \\
\hline Crosses & $3.17 \pm 0.85$ & $1.88 \pm 0.47$ \\
\hline \multicolumn{3}{|l|}{ Morris Water maze } \\
\hline \multicolumn{3}{|l|}{ First acquisition trial } \\
\hline Duration (s) & $95.37 \pm 10.7$ & $90.875 \pm 11.24$ \\
\hline Distance (cm) & $1456.17 \pm 183.7$ & $1238.14 \pm 134.47$ \\
\hline \multicolumn{3}{|l|}{ Last acquisition trial } \\
\hline Duration (s) & $27.22 \pm 3.3$ & $38.71 \pm 9.65$ \\
\hline Distance (cm) & $497.41 \pm 63.55$ & $557.36 \pm 167.69$ \\
\hline
\end{tabular}

Data are expressed as means \pm SEM. For details, see Materials and Methods. Genotype-based comparisons were performed using Student's $t$ test for independent samples $\left({ }^{*} p<0.01{ }^{* *} p<0.05\right)$.

(Fig. 5A). Similar results were found during extinction. Thus, a two-way ANOVA (genotype $\times$ day) only yielded a significant effect for the day factor $\left(F_{(14,364)}=2.88 ; p<0.01\right)$, revealing that both groups significantly decreased the number of lever presses (extinction) across these sessions. After the establishment of a stable extinction baseline, the ability of the noncontingent reintroduction of the $\mathrm{CS}^{+}$(light) to reinstate lever pressing behavior in both WT and GluR-C KO was assessed. This effect was evaluated as a percentual increase over the number of lever presses observed in the last extinction session of each group. A Student's $t$ test for independent samples comparing both genotypes revealed the increase in the number of lever presses on the previously designated active lever to be significantly higher in WT than in GluR-C knock-out mice $\left(t_{(25)}=2.06 ; p<0.05\right)$ (Fig. $5 B$ ).

As depicted in Figure 6A, GluR-C knock-out mice did not differ from their WT littermates in voluntary ethanol consumption at any concentration tested. Thus, a two-way ANOVA (genotype $X$ ethanol concentration) only revealed a significant effect for the ethanol concentration $\left(F_{(4,220)}=36.79 ; p<0.01\right)$ but not for the genotype or the interaction genotype $\times$ ethanol concentration. Alcohol preference data showed a similar results pattern (Fig. $6 B$ ), that is, only yielding a significant effect with regard to the ethanol concentration factor $\left(F_{(4,220)}=30.02 ; p<0.01\right)$. However, the resumption of ethanol drinking after 3 weeks of abstinence showed a marked difference between genotypes. In fact, a two-way ANOVA (genotype $\times$ day) comparing ethanol consumption $3 \mathrm{~d}$ before and $3 \mathrm{~d}$ after this deprivation phase revealed a significant effect of the day factor $\left(F_{(5,55)}=2.82 ; p<\right.$ $0.01)$ and the interaction between both factors $\left(F_{(5,255)}=3.99\right.$; $p<0.01)$. Post hoc comparisons revealed that ethanol consumption was similar in WT and GluR-C knock-out mice during the baseline period and that both groups significantly increased $(p<$
0.05) alcohol consumption after the deprivation phase. However, this increase was markedly blunted in GluR-C knock-out mice on day $1(p<0.01)$ (Fig. $6 C)$.

\section{Discussion}

In the present study, we show that the administration of the AMPA receptor antagonist GYKI 52466 dose-dependently reduces ethanol-seeking behavior as assessed in the reinstatement paradigm and suppresses the occurrence of an ADE. Furthermore, our second set of data revealed that genetic deletion of GluR-C resulted in an identical phenotype. Importantly, in addition to a slight hypolocomotor response in the open field in GluR-C KO mice, these results were observed in the absence of any apparent major physiological or behavioral (including baseline ethanol consumption) abnormality. Therefore, our results suggest that AMPA receptors containing the GluR-C subunit display a prominent role in ethanol-seeking and relapse behavior and that the effects of GYKI 52466 might be related to its inhibitory effects on AMPA receptors containing the GluR-C subunit.

The ability of GYKI 52466 to reduce ethanol-seeking behavior seems to be in agreement with previous studies concerning cocaine- (Cornish and Kalivas, 2000) as well as ethanol-seeking behavior, using the nonspecific AMPA/kainate antagonist CNQX (Bäckstrom and Hyytiä, 2004). Thus, the findings of the present study provide additional support regarding the proposed involvement of this glutamate receptor subtype in drug craving and relapse. Interestingly, this seems to be a quite specific effect, because it is known that similar doses of GYKI 52466 do not affect operant ethanol self-administration (Stephens and Brown, 1999), therefore arguing against a major involvement of AMPA receptors in the primary reinforcing effects of alcohol. At present, it is unclear how AMPA receptor antagonism blocks alcohol seeking and relapse, because this mechanism seems to be independent of the reinforcing value of ethanol. Moreover, the fact that the effects of GYKI 52466 were observed, when administered just before and during the relapse episode, suggests that AMPA receptor antagonism is involved in the expression rather than in the induction of the putative neuroadaptive relapse-inducing changes produced by alcohol and/or alcohol cues exposure. This proposal seems to be in agreement with previous reports that showed that GYKI 52466 administration blocks the expression of the neuroadaptive changes underlying ethanol-induced locomotor sensitization (Broadbent et al., 2003).

In recent years, it has been suggested that a specific AMPA receptor subunit composition provides a fine-tuning in neuroadaptive processes derived from chronic drug exposure, including those that presumably control craving and relapse behavior ( $\mathrm{Lu}$ et al., 2003; Tang et al., 2004; Yuferov et al., 2005). However, the contribution of different AMPA receptor subunits in this respect is less clear. Mead and Stephens (2003a,b) observed that GluR-A and GluR-B knock-out mice display very specific deficits in stimulus-reward learning and advanced the hypothesis that altered expression of GluR-A or GluR-B subunits should influence specific aspects of cue-induced drug responses. More specifically, these authors proposed that genetic GluR-A or GluR-B deletions should influence cue-induced behavior in a way similar to that of lateral and central amygdala lesions, respectively. Unexpectedly, this proposal has not been confirmed, and the few published studies involving GluR-A or GluR-B knock-out mice have not been able to establish a clear role for these AMPA receptor subunits. Thus, GluR-A overexpression in the shell of the nucleus accumbens was found not to influence cue-induced cocaine relapsing behavior (Sutton et al., 2003), and it is also known that the 
alcohol deprivation effect in GluR-A knock-out mice is not different from that of wild-type controls (Cowen et al., 2003). Moreover, conflicting findings regarding cocaine-induced place preference in GluR-A knock-out mice have been reported previously (Dong et al., 2004; Mead et al., 2005). The role of the GluR-B subunit in this regard has been less studied thus far, in part because of the multiple behavioral abnormalities displayed by GluR-B knock-out mice (Gerlai et al., 1998; Mead and Stephens, 2003b); however, they also show normal cocaineinduced, but not food-induced, place preference (Mead et al., 2005). Therefore, although there is an increasing interest in the possible role of AMPA receptor subunit composition in drug-seeking behavior (Self and Choi, 2004), this genotypephenotype correlation remains elusive and, indeed, similar consequences in relapsing behavior have been hypothesized after the genetic deletion of different AMPA receptor subunits (Mead and Stephens, 2003a,b).

Considering the abovementioned conflicting evidence and the fact that ethanol administration produces long-lasting adaptive changes in GluR-C expression (Brückner et al., 1997; Dettmer et al., 2003), we focused on the role of this AMPA receptor subunit with regard to ethanol-seeking and relapse behavior. By the use of two separate cohorts of mice and by means of two different animal models, namely the cue-induced reinstatement and ADE paradigms, we could show that the GluR-C subunit is involved in alcohol seeking and relapse. Thus, although ethanol consumption in those animals was not different from that observed in littermate controls, alcohol-seeking behavior after active extinction of the self-administration response was markedly blunted in GluR-C knock-out mice, and resumption of alcohol selfadministration after a deprivation period was reduced in these animals. Therefore, our results seem to point out an important role for GluR-C in alcohol seeking and relapse-like behavior.

However, as in the case of GluR-A and GluR-B knock-out mice (Mead and Stephens, 2003a,b), the observation of adaptive changes in the expression of other AMPA receptor subunits provides an alternative interpretation to our findings. Thus, at least in areas with a constitutively high proportion of GluR-Ccontaining AMPA receptors (i.e., cerebellum), the deletion of this subunit leads to reduced expression of GluR-A, GluR-B, and GluR-D. Such a general downregulation should thus result in a reduction in the total number of available AMPA receptors and might lead to potential phenotypic consequences. Indeed, we observed that the general decrease in the expression of all AMPA subunits in the cerebellum was accompanied with an altered motor performance on the rotarod and on the beam balance tests. Conversely, in the hippocampus (with low levels of constitutive GluR-C expression), GluR-A, GluR-B, and GluR-D subunit expression was normal, and performance in a hippocampusdependent task (Morris water maze) was unaltered. Therefore, the striking parallelism between the phenotype of GluR-C knockout mice and the effects of GYKI 54266 in ethanol relapse-like
A

B

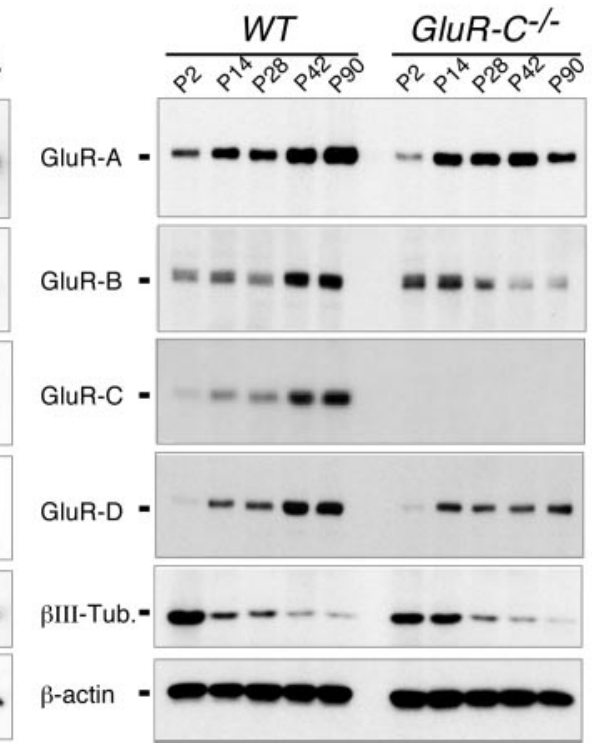

WT GluR-C-/-

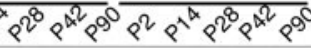

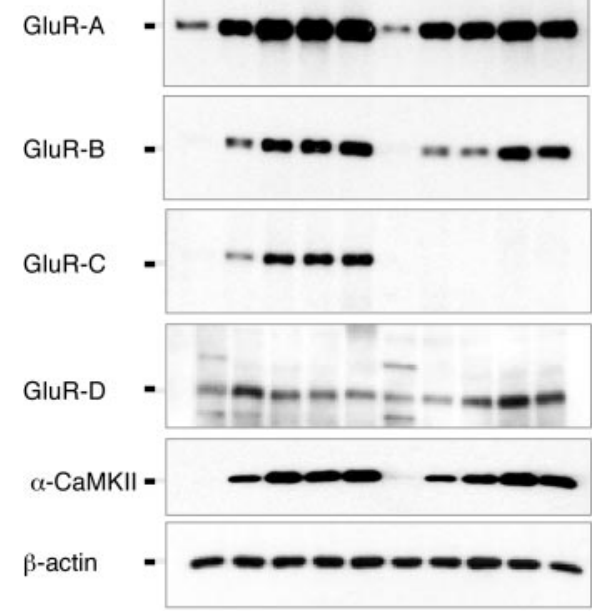

Figure 4. $A, B$, Changes in AMPA receptor subunit expression of the AMPA receptor subunits GluR-A, GluR-B, GluR-C, and GluR-D in hippocampus ( $\boldsymbol{A}$ ) and cerebellum (B) of wild-type (WT) and GluR-C knock-out (GluR-C $-/-$ ) mice from P2 to P90. Total proteins of the hippocampus and the cerebellum were isolated, and for each sample, $10 \mu \mathrm{g}$ of protein was separated on a $7.5 \%$ tively. Loading was controlled by $\beta$-actin. The experiment was repeated with at least three sets of mice. One representative
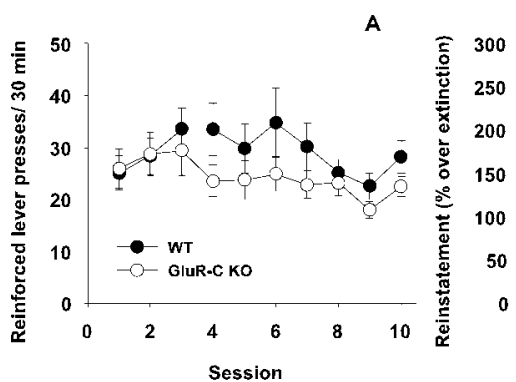

B

Figure 5. Operant ethanol self-administration and cue-induced reinstatement in WT and GluR-C knock-out mice ( $n=14$ per group). $A$, Mean \pm SEM of ethanol (10\% v/v)-reinforced lever presses per session during the last 10 self-administration sessions. $\boldsymbol{B}$, Mean \pm SEM of lever presses in the previously ethanol-reinforced lever for each genotype elicited by a $\mathrm{CS}^{+}$(light) after 15 extinction sessions (for details, see Materials and Methods). Open and filled symbols depict data for WT and GluR-C knock-out mice, respectively ( ${ }^{*} p<0.05$ between genotypes).

behavior could arise from a specific role of this protein or could be secondary to a general reduction in the number of available AMPA receptors in some brain areas. Unfortunately, in the absence of specific inhibitors for GluR-C containing AMPA receptors or a precise knowledge of the neuroanatomical bases for phenomena such as cue-induced reinstatement or ADE, this question cannot yet be solved.

In summary, the results of the present study highlight an important role for the AMPA receptor in alcohol-seeking and relapse-like behavior. The specific involvement of GluR-C regarding those effects cannot be fully delineated at present. In addition, the fact that its deletion results in adaptive changes in the expression of other AMPA subunits, at least in some brain regions, allows for an alternative mechanism based on a sitespecific reduction in the number of available AMPA receptors. 

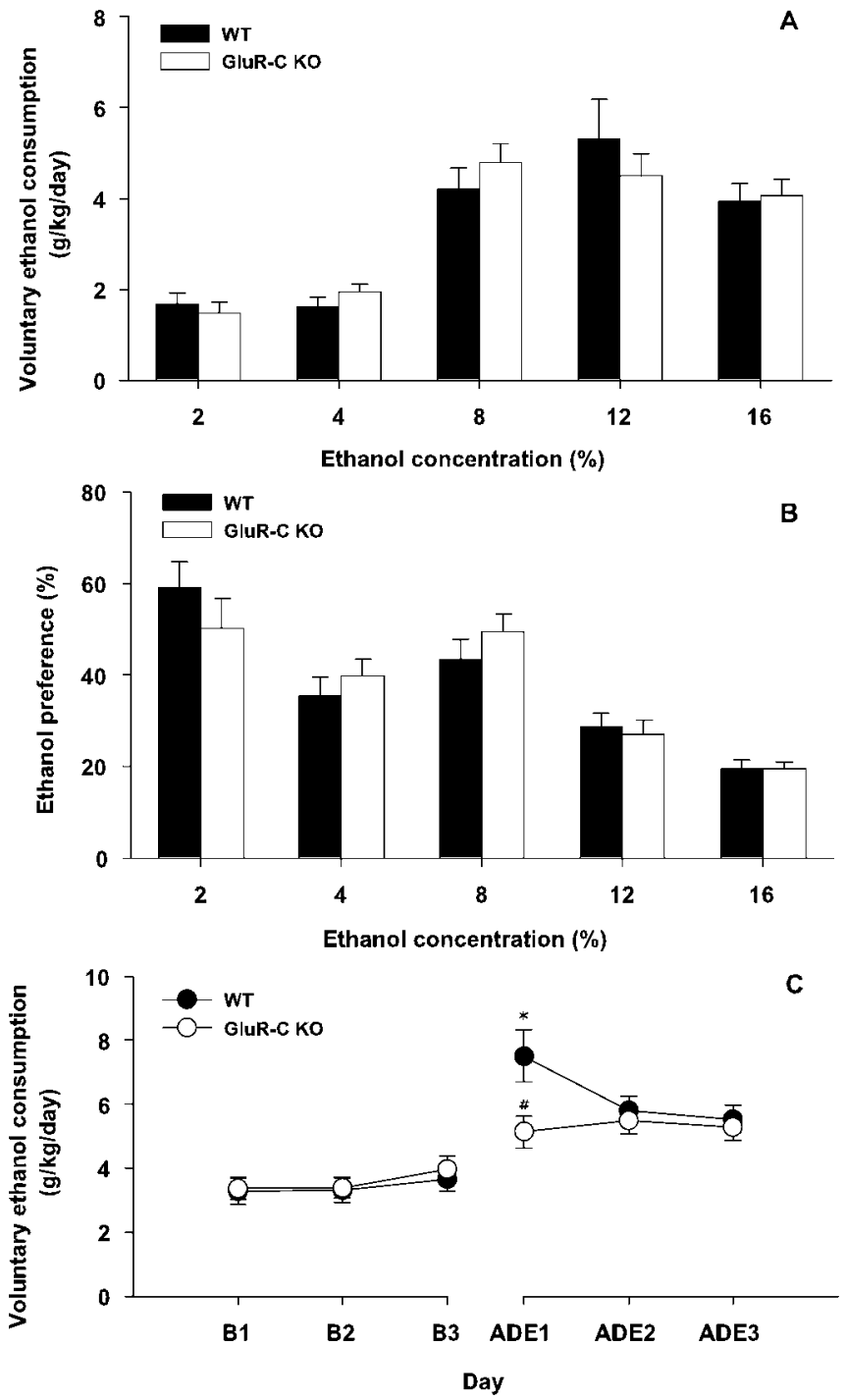

Figure 6. Two-bottle free-choice ethanol self-administration, preference and al cohol deprivation effect in WT ( $n=26)$ and GluR-C knock-out mice $(n=32)$. $A$, Ethanol consumption (grams per kilogram per day) per ethanol concentration. $\boldsymbol{B}$, Ethanol preference observed during the same conditions depicted in $\boldsymbol{A}$. C depicts ADE in the same group of animals by comparing ethanol self-administration $3 \mathrm{~d}$ before and $3 \mathrm{~d}$ after a 3 week deprivation period. All data are expressed as mean \pm SEM (for details, see Materials and Methods) $\left({ }^{*} p<0.01\right.$ between genotypes). B1, Baseline 1; B2, baseline 2; B3, baseline 3.

Thus, at least from a therapeutic perspective, the data obtained in this investigation points in the direction with respect to the suitability of addressing pharmacological interventions at AMPA receptors in reducing craving and relapse in alcoholic and probably other drug-addicted patients. Additional studies ought to be undertaken to determine, if the therapeutic use of AMPA antagonists can be further refined, by targeting specific AMPA receptor populations, defined according to their particular subunit composition.

\section{References}

Bachteler D, Spanagel R (2005) Glutamatergic compounds: preclinical data. In: Drugs for relapse prevention (Spanagel R, Mann KF, eds), pp 205-216. Basel: Birkhäuser.

Bachteler D, Economidou D, Danysz W, Ciccocioppo R, Spanagel R (2005) The effects of acamprosate and neramexane on cue-induced reinstatement of ethanol-seeking behavior in rat. Neuropsychopharmacology 30:1104-1110.
Bäckstrom P, Hyytiä P (2004) Ionotropic glutamate receptor antagonists modulate cue-induced reinstatement of ethanol-seeking behavior. Alcohol Clin Exp Res 28:558-565.

Bäckstrom P, Bachteler D, Koch S, Hyytia P, Spanagel R (2004) mGluR5 antagonist MPEP reduces ethanol-seeking and relapse behavior. Neuropsychopharmacology 29:921-928.

Broadbent J, Kampmueller KM, Koonse SA (2003) Expression of behavioural sensitization to ethanol in DBA/2J mice: The role of NMDA and non-NMDA glutamate receptors. Psychopharmacology 167:225-234.

Brückner MK, Rossner S, Arendt T (1997) Differential changes in the expression of AMPA receptors genes in rat brain after chronic exposure to ethanol: an in situ hybridization study. J Hirnforsch 38:369-376.

Chourbaji S, Hellweg R, Brandis D, Zorner B, Zacher C, Lang UE, Henn FA, Hortnagl H, Gass P (2004) Mice with reduced brain-derived neurotrophic factor expression show decreased choline acetyltransferase activity, but regular brain monoamine levels and unaltered emotional behavior. Brain Res Mol Brain Res 121:28-36.

Cornish JL, Kalivas PW (2000) Glutamate transmission in the nucleus accumbens mediates relapse in cocaine addiction. J Neurosci 20:RC89(1-5).

Cowen MS, Schroff KC, Gass P, Sprengel R, Spanagel R (2003) Neurobehavioral effects of alcohol in AMPA receptor subunit (GluR1) deficient mice. Neuropharmacology 45:325-333.

Dahchour A, De Witte P (2000) Ethanol and amino acids in the central nervous system: assessment of the pharmacological actions of acamprosate. Prog Neurobiol 60:343-362.

Dahchour A, De Witte P (2003) Effects of acamprosate on excitatory amino acids during multiple ethanol withdrawal periods. Alcohol Clin Exp Res $27: 465-470$.

Dettmer TS, Barnes A, Iqbal U, Bailey CD, Reynolds JN, Brien JF, Valenzuela CF (2003) Chronic prenatal ethanol exposure alters ionotropic glutamate receptor subunit protein levels in the adult guinea pig cerebral cortex. Alcohol Clin Exp Res 27:677-681.

Di Ciano P, Everitt BJ (2001) Dissociable effects of antagonism of NMDA and AMPA/KA receptors in the nucleus accumbens core and shell on cocaine-seeking behavior. Neuropsychopharmacology 25:341-360.

Dong Y, Saal D, Thomas M, Faust R, Bonci A, Robinson T, Malenka RC (2004) Cocaine-induced potentiation of synaptic strength in dopamine neurons: behavioral correlates in GluRA(-/-) mice. Proc Natl Acad Sci USA 101:14282-14827.

Gerlai R, Henderson JT, Roder JC, Jia Z (1998) Multiple behavioral anomalies in GluR2 mutant mice exhibiting enhanced LTP. Behav Brain Res 5:37-45.

Hölter S, Danysz W, Spanagel R (2000) Novel uncompetitive N-methyl-Daspartate (NMDA)-receptor antagonist MRZ 2/579 suppresses ethanol intake in long-term ethanol-experienced rats and generalizes to ethanol cue in drug discrimination procedure. J Pharmacol Exp Ther 292:545-552.

Krystal JH, Petrakis IL, Mason G, Trevisan L, D'Souza DC (2003) $\mathrm{N}$-methyl-D-aspartate glutamate receptors and alcoholism: reward, dependence, treatment, and vulnerability. Pharmacol Ther 99:79-94.

Le A, Shaham Y (2002) Neurobiology of relapse to alcohol in rats. Pharmacol Ther 94:137-156.

Lee G, Saito I (1998) Role of nucleotide sequences of loxP spacer region in Cre-mediated recombination. Gene 216:55-65.

Littleton J (1995) Acamprosate in alcohol dependence: how does it work? Addiction 90:1179-1188.

Lu L, Grimm JW, Shaham Y, Hope BT (2003) Molecular neuroadaptations in the accumbens and ventral tegmental area during the first 90 days of forced abstinence from cocaine self-administration in rats. J Neurochem 85:1604-1613.

Mann K (2004) Pharmacotherapy of alcohol dependence: a review of the clinical data. CNS Drugs 18:485-504.

Mead AN, Stephens DN (2003a) Selective disruption of stimulus-reward learning in glutamate receptor grial knock-out mice. J Neurosci 23:1041-1048.

Mead AN, Stephens DN (2003b) Involvement of AMPA receptor GluR2 subunits in stimulus-reward learning: evidence from glutamate receptor gria2 knock-out mice. J Neurosci 23:9500-9508.

Mead AN, Brown G, Le Merrer J, Stephens DN (2005) Effects of deletion of gria1 or gria2 genes encoding glutamatergic AMPA-receptor subunits on place preference conditioning in mice. Psychopharmacology 179:164-171. 
Olive MF, McGeehan AJ, Kinder JR, McMahon T, Hodge CW, Janak PH, Messing RO (2005) The mGluR5 antagonist 6-methyl-2(phenylethynyl)pyridine decreases ethanol consumption via a protein kinase C epsilon-dependent mechanism. Mol Pharmacol 67:349-355.

Sans N, Vissel B, Petralia RS, Wang YX, Chang K, Roylge GA, Wang CY, O'Gorman S, Heinemann SF, Wenthold RJ (2003) Aberrant formation of glutamate receptor complexes in hippocampal neurons of mice lacking the GluR2 AMPA receptor subunit. J Neurosci 23: 9367-9373.

Scherbel U, Raghupathi R, Nakamura M, Saatman KE Trojanowski JQ, Neugebauer E, Marino MW, McIntosh TK (1999) Differential acute and chronic responses of tumor necrosis factor-deficient mice to experimental brain injury. Proc Natl Acad Sci USA 96:8721-8726.

Schroeder JP, Overstreet DH, Hodge CW (2005) The mGluR5 antagonist MPEP decreases operant ethanol self-administration during maintenance and after repeated alcohol deprivations in alcohol-preferring $(\mathrm{P})$ rats. Psychopharmacology (Berl) 179:262-270.

Schwenk F, Baron U, Rajewsky K (1995) A cre-transgenic mouse strain for the ubiquitous deletion of loxP-flanked gene segments including deletion in germ cells. Nucleic Acids Res 23:5080-5081.

Self DW, Choi KH (2004) Extinction-induced neuroplasticity attenuates stress-induced cocaine seeking: a state-dependent learning hypothesis. Stress 7:145-155.

Spanagel R, Hölter S (1999) Long-term alcohol self-administration with repeated alcohol deprivation phases: an animal model of alcoholism? Alcohol Alcohol 34:231-243.

Spanagel R, Sanchis-Segura C (2003) The use of transgenic mice to study addictive behavior. Clin Neurosci Res 3:325-331.

Spanagel R, Pendyala G, Abarca C, Zghoul T, Sanchis-Segura C, Magnone
MC, Lascorz J, Depner M, Holzberg D, Soyka M, Schreiber S, Matsuda F, Lathrop M, Schumann G, Albrecht U (2005) The clock gene Per2 influences the glutamatergic system and modulates alcohol consumption. Nat Med 11:35-42.

Stephens DN, Brown G (1999) Disruption of operant oral selfadministration of ethanol, sucrose, and saccharin by the AMPA/kainate antagonist, NBQX, but not the AMPA antagonist, GYKI 52466. Alcohol Clin Exp Res 23:1914-1920.

Sutton MA, Schmidt EF, Choi KH, Schad CA, Whisler K, Simmons D, Karanian DA, Monteggia LM, Neve RL, Self DW (2003) Extinction-induced upregulation in AMPA receptors reduces cocaine-seeking behaviour. Nature 421:70-75.

Tang W, Freeman WM, Liang B, Hemby SE (2004) Alterations in ionotropic glutamate receptor subunits during binge cocaine selfadministration and withdrawal in rats. J Neurochem 89:1021-1033.

Tsai G, Coyle JT (1998) The role of glutamatergic neurotransmission in the pathophysiology of alcoholism. Annu Rev Med 49:173-184.

Tsuzuki K, Lambolez B, Rossier J, Ozawa S (2001) Absolute quantification of AMPAR subunit mRNAs in single hippocampal neurons. J Neurochem 77:1650-1659.

Tzschentke TM, Schmidt WJ (2003) Glutamatergic mechanisms in addiction. Mol Psychiatry 8:373-382.

Vengeliene V, Bachteler D, Danysz W, Spanagel R (2005) The role of the NMDA receptor in alcohol relapse: a pharmacological mapping study using the alcohol deprivation effect. Neuropharmacology 488:822-829.

Yuferov V, Nielsen D, Butelman E, Kreek MJ (2005) Microarray studies of psychostimulant-induced changes in gene expression. Addict Biol 10:101-118. 